\title{
Internet Paradox Revisited
}

\author{
Robert Kraut $^{\mathrm{a}}$, Sara Kiesler ${ }^{\mathrm{a}}$, Bonka Boneva ${ }^{\mathrm{a}}$, \\ Jonathon Cummings ${ }^{\mathrm{a}}$, Vicki Helgeson ${ }^{\mathrm{b}}$, and Anne Crawford ${ }^{\mathrm{a}}$ \\ ${ }^{\mathrm{a}}$ Human Computer Interaction Institute \\ ${ }^{\mathrm{b}}$ Department of Psychology \\ Carnegie Mellon University
}

October 12, 2001

Version 16.2

Journal of Social Issues

Authors note. This research was funded by the National Science Foundation (Grants IRI9408271 and 9900449). In addition, initial data collection was supported through grants from Apple Computer Inc, AT\&T Research, Bell Atlantic, Bellcore, CNET, Intel Corporation, Interval Research Corporation, Hewlett Packard Corporation, Lotus Development Corporation, the Markle Foundation, The NPD Group, Nippon Telegraph and Telephone Corporation (NTT), Panasonic Technologies, the U.S. Postal Service, and U S West Advanced Technologies. Tridas Mukophadhyay and William Scherlis participated in designing and carrying out the original HomeNet studies. Email addresses of the authors are robert.kraut@andrew.cmu.edu, kiesler@andrew.cmu.edu,bboneva@andrew.cmu.edu, jnc@andrew.cmu.edu, vh2e@andrew.cmu.edu, amc@cs.cmu.edu 


\begin{abstract}
Kraut et al. (1998) reported negative effects of using the Internet on social involvement and psychological well-being among new Internet users in 1995-1996. We called the effects a "paradox" because participants used the Internet heavily for communication, which generally has positive effects. A 3-year follow-up of 208 of these respondents found that negative effects dissipated. We also report findings from a longitudinal survey in 1998-99 of 406 new computer and television purchasers. This sample generally experienced positive effects of using the Internet on communication, social involvement, and well-being. However, consistent with a "rich get richer" model, using the Internet predicted better outcomes for extraverts and those with more social support but worse outcomes for introverts and those with less support.
\end{abstract}




\section{Internet Paradox Revisited}

With the rapidly expanding reach of the Internet into everyday life, it is important to understand its social impact. One reason to expect significant social impact is the Internet's role in communication. From the early days of networked mainframe computers to the present, interpersonal communication has been the technology's most frequent use (Sproull \& Kiesler, 1991). Over $90 \%$ of people who used the Internet during a typical day in 2000, sent or received email (Pew Internet Report, 2000), far more than used any other online application or information source. Using email leads people to spend more time online and discourages them from dropping Internet service (Kraut, Mukhopadhyay, Szczypula, Kiesler, \& Scherlis, 2000). Other Internet communication services are increasingly popular-instant messaging, chat rooms, multi-user games, auctions, and myriad groups comprising "virtual social capital" on the Internet (Putnam, 2000, pg. 170).

If communication dominates Internet use for a majority of its users, there is good reason to expect that the Internet will have positive social impact. Communication, including contact with neighbors, friends, and family, and participation in social groups, improves people's level of social support, their probability of having fulfilling personal relationships, their sense of meaning in life, their self-esteem, their commitment to social norms and to their communities, and their psychological and physical well-being (e.g., Cohen \& Wills, 1985; Diener, Sul, Lucas, \& Smith, 1999; Thoits, 1983; Williams, Ware, \& Donald, 1981).

Through its use for communication, the Internet could have important positive social effects on individuals (e.g., McKenna \& Bargh, 2000; McKenna, Green, \& Gleason, this issue), groups and organizations (e.g., Sproull \& Kiesler, 1991), communities (e.g., Wellman, Quan, 
Witte \& Hampton, 2001; Borgida, Sullivan, Oxendine, Jackson, Riedel, \& Gang, this issue), and society at large (e.g., Hiltz \& Turoff, 1978). Because the Internet permits social contact across time, distance, and personal circumstances, it allows people to connect with distant as well as local family and friends, co-workers, business contacts, and with strangers who share similar interests. Broad social access could increase people's social involvement, as the telephone did in an early time (e.g., Fischer, 1992). It also could facilitate the formation of new relationships (Parks, \& Roberts, 1998), social identity and commitment among otherwise isolated persons (McKenna \& Bargh, 1998), and participation in groups and organizations by distant or marginal members (Sproull \& Kiesler, 1991).

Whether the Internet will have positive or negative social impact, however, may depend upon the quality of people's online relationships and upon what people give up to spend time online. Stronger social ties generally lead to better social outcomes than do weaker ties (e.g., Wellman \& Wortley, 1990). Many writers have worried that the ease of Internet communication might encourage people to spend more time alone, talking online with strangers or forming superficial "drive by" relationships, at the expense of deeper discussion and companionship with friends and family (e.g., Putnam, 2000, pg. 179). Further, even if people use the Internet to talk with close friends and family, these online discussions might displace higher quality face-to-face and telephone conversation (e.g., Cummings, Butler \& Kraut, in press; Thompson \& Nadler, this issue).

Research has not yet led to consensus on either the nature of social interaction online or its effects on social involvement and personal well-being. Some survey research indicates that online social relationships are weaker than off-line relationships (Parks \& Roberts, 1998), that people who use email regard it as less valuable than other modes of communication for 
maintaining social relationships (Cummings et al., in press; Kraut \& Attewell, 1996), that people who use email heavily have weaker social relationships than those who do not (Riphagen \& Kanfer, 1997) and that people who use the Internet heavily report spending less time communicating with their families (Cole, 2000). In contrast, other survey research shows that people who use the Internet heavily report more social support and more in-person visits with family and friends than those who use it less (Pew Internet Report, 2000). Because this research has been conducted with different samples in different years, it is difficult to identify central tendencies and changes in these tendencies with time. Further, the cross-sectional nature of the research makes it impossible to distinguish self-selection (in which socially engaged and disengaged people use the Internet differently) from causation (in which use of the Internet encourages or discourages social engagement).

A longitudinal study by Kraut, Patterson, Lundmark, Kiesler, Mukophadhyay and Scherlis (1998) was one of the first to assess the causal direction of the relationship between Internet use and social involvement and psychological well-being. The HomeNet field trial followed 93 households in their first 12-18 months online. The authors had predicted that the Internet would increase users' social networks and the amount of social support to which they had access. The consequence should be that heavy Internet users would be less lonely, have better mental health, and be less harmed by the stressful life events they experienced (Cohen, \& Wills, 1985). The sample as a whole reported high well-being at the start of the study. Contrary to predictions, however, the association of Internet use with changes in the social and psychological variables showed that participants who used the Internet more heavily became less socially involved and more lonely than light users and reported an increase in depressive 
symptoms. These changes occurred even though participants' dominant use of the Internet was communication.

These findings were controversial. Some critics argued that because the research design did not include a control group without access to the Internet, external events or statistical regression could have been responsible for participants' declines in social involvement and psychological well-being (e.g., Gross, Juvonen, \& Gable, this issue ; Shapiro, 1999). However, these factors would have affected heavy and light Internet users similarly, so could not account for the differences in outcomes between them.

A more pertinent problem noted in the original HomeNet report is the unknown generalizability of the results over people and time. The participants in the original study were an opportunity sample of families in Pittsburgh. In 1995 and 1996, when they began the study, they initially had higher community involvement and more social ties than the population at large. In addition, they had little experience online, and few of their family and friends had Internet access. One possibility is that using the Internet disrupted this group's existing social relationships. Had the study begun with a more socially deprived sample or more recently, when more of the population was online, the group's use of the Internet for social interaction might have led to more positive effects. In addition, some critics questioned the particular measures of social involvement and well-being deployed in this study (e.g., Shapiro, 1999).

The present article addresses these issues of generalizability through a follow up of the original HomeNet sample and a new longitudinal study. The rationale for both studies is similar. If use of the Internet changes the amount and type of interpersonal communication people engage in and the connections they have to their friends, family, and communities, then it should also influence a variety of psychological outcomes, including their emotions, self-esteem, 
depressive symptoms and reactions to stressors being (e.g., Cohen \& Wills, 1985; Diener, Sul, Lucas, \& Smith, 1999; Thoits, 1983; Williams, Ware, \& Donald, 1981). The follow-up study examined the longer-term impact of Internet use on those in the original HomeNet sample, providing a second look at a group for whom initial Internet use had poor effects. It retained the outcome measures collected in original HomeNet study.

The second study followed a new sample in the Pittsburgh area, from 1998 and 1999. It compared an explicit control-group of those who had recently purchased a television set with those who purchased a computer. It also examines the impact of the Internet on a broader variety of social and psychological outcome measures than did the original HomeNet study. The goal was not to make differentiated predictions for each measure, but to see if using the Internet had similar consequences across a variety of measures of social involvement and psychological wellbeing. The sample was sufficiently large to permit an analysis of the impact of individual differences in personality and social resources on Internet usage and outcomes. In particular, the research examines whether using the Internet had different consequences for people differing in extraversion and in social support. As discussed further in the introduction to Study 2, people differing in extraversion and social support are likely use the Internet in different ways. In addition, they are likely to have different social resources available in their off-line lives, which could change the benefits they might gain from social resources they acquire online.

Study 1: Follow-up of the original HomeNet sample.

The data are from 208 members of 93 Pittsburgh families, to whom we provided a computer and access to the Internet in 1995 or 1996. The families were recruited through four high school journalism programs and four community development organizations in 8 Pittsburgh 
neighborhoods. The sample was more demographically diverse than was typical of Internet users at the time. Details of the sampling and research protocol are described in Kraut et al. (1996).

The analyses of social impact reported in Kraut et al. (1998) were drawn from Internet usage records and from surveys given just before participants began the study and again in May 1997. Server software recorded participants' use of the Internet- hours online, email volume, and Web sites visited per week. The surveys included four measures of social involvement (time spent in family communication, size of local social network, size of distant social network, and perceived social support [Cohen, Mermelstein, Kamarck, \& Hoberman, 1984]), and three wellestablished measures of psychological well-being: the UCLA Loneliness Scale (Russell, Peplau, \& Cutrona, 1980), the Daily Life Hassles Scale, a measure of daily-life stress (Kanner, Coyne, Schaefer, \& Lazarus, 1981), and the Center for Epidemiological Studies’ Depression Scale (Radloff, 1977). It included the demographic characteristics of age, gender, household income, and race as control variables, because there is evidence that these factors influence both the amount of Internet use and the social and psychological outcomes (e.g., Von Dras \& Siegler, 1997; Magnus, Diener, Fujita, Payot, 1993). We also included the personality trait of extraversion (Bendig, 1962) as a control variable, because extraversion is often associated with well-being (Diener, et al, 1999) and may also influence the way people use the Internet. However, the sample was too small to examine statistical interaction involving the extraversion measure. See Table 1 for basic statistics and other information about these variables. 
Kraut et al. (1998) used a regression analysis of the effect of hours of Internet use on social involvement and psychological well-being in 1997 (Time 2), controlling for scores on these outcome measures at the pretest (Time 1) and the demographic and personality control variables. The follow-up study re-examines the impact of use of the Internet by adding a third survey, administered in February 1998 (Time 3). For about half the participants, the final survey came nearly 3 years after they first used the Internet; for the other half, the final survey came nearly 2 years later.

\section{Method}

All longitudinal research faces the potential of participant attrition. Our research was especially vulnerable because we had not planned initially to follow the participants for more than one year. Many of the high school students in the original sample graduated and moved to college. Further, technology changed rapidly during this period, and some participants changed Internet providers, ending our ability to monitor their Internet use. Of the 335 people who qualified for participation in the original study, 261 returned a pretest survey at Time 1 (78\%), 227 returned a survey at Time $2(68 \%)$, and 154 returned a survey at Time $3(46 \%)$. Because this research is fundamentally about changes in social and psychological outcomes, we limit analysis to 208 participants who completed a minimum of 2 out of 3 surveys.

We used a longitudinal panel design to examine the variables that influenced changes in social involvement and psychological well-being from Time 1 to Time 2, and from Time 2 to Time 3. The measure of Internet use is the average hours per week a participant spent online between any two surveys, according to automated usage records (i.e., weekly use between Times 1 and 2 and between Time 2 and 3). Because this variable was highly skewed, we used a log transformation. When assessing the impact of Internet use on social involvement and 
psychological well-being at one time, we statistically controlled for the prior level of social involvement and psychological well-being by including the lagged dependent variable as a control variable in the model. Since this analysis controls for participants' demographic characteristics and the lagged outcome, one can interpret the coefficients associated with Internet use as the effect of Internet use on changes in these outcomes (Cohen \& Cohen, 1983, p. 417422). (For example, when examining the effect of Internet use on loneliness at Times 2 and 3, we included the lagged variable for loneliness at Times 1 and 2, respectively, in the model to control for the effects of prior loneliness on Internet use and on subsequent loneliness.

As demographic control variables, we included adult status ( 0 if age $<=18 ; 1$ if age $>$ $18)$, gender $(0=$ female; $1=$ male $)$, race $(0=$ non-white; $1=$ white $)$ and household income. Because teens use the Internet substantially more than adults and in different ways (Kraut et al, 1998), we included the generation X Internet use interaction to determine whether the Internet had similar effects on both generations. Because the personality trait of extraversion is likely to influence social involvement, Bendig's (1962) measure of extraversion was included as a control variable when predicting social support and the size of local and distant social circles. Because daily-life stress is a risk factor for psychological depression, we included Kanner, Coyne, Schaefer, \& Lazarus' (1981) hassles scale as a control variable when predicting depressive symptoms.

The analyses were conducted using the xtreg procedure in Stata (StataCorp, 2001) for cross-sectional time series analyses with independent variables modeled as a fixed effects and participant modeled as a random effect. For the dependent measures listed in Table 2, the basic

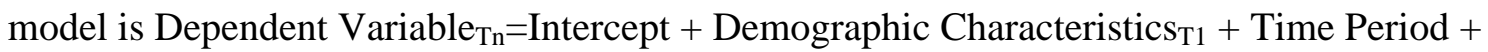

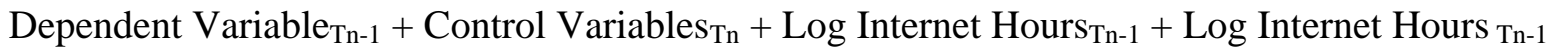
$\mathrm{X}$ Time Period + Log Internet Hours ${ }_{\mathrm{Tn}-1} \mathrm{X} \mathrm{Generation}_{\mathrm{T} 1}$. In the model Dependent Variable Tn $_{\mathrm{n}}$ 
a measure of social involvement or psychological well-being at the end of the first or second time period and Dependent Variable ${ }_{T n-1}$ represents the same measure administered in the previous time period. The analyses of particular interest are the main effects of Internet use on subsequent measures of social involvement and psychological well-being and the statistical interactions of Internet use and time period on these outcomes. The main effect of Internet use assesses the cumulative impact of Internet use over the two or three years of the study, and the interaction of Internet use with time period assesses whether this impact is the same in the early period (previously reported in Kraut et al., 1998) and in the more recent period.

$\underline{\text { Results }}$

Table 2 shows results from the analyses. Kraut et al. (1998) showed Internet use was associated with declines in family communication, in the number of people in participants' local and distant social circles, and with increases in loneliness, depressive symptoms, and daily-life stress. Of these effects, Internet use over the longer period tested in the current analyses is associated only with increases in stress. Two significant Internet use $\mathrm{X}$ time period interactions suggest that Internet use had different effects early and late in respondents' use of the Internet. In particular, depressive symptoms significantly increased with Internet use during the first period but significantly declined with Internet use during the second period (for the interaction, $\mathrm{p}<.05$ ). Loneliness significantly increased with Internet se during the first period but was not associated with Internet use during the second period (for the interaction, $p<.01$ ). Whether these differences in results over time reflect participants' learning how to use the Internet as they gain more experience or whether they reflect changes in the Internet itself over this period is a topic we will return to in the discussion. 
Because teenagers use the Internet more than their parents and because teens and adults differed on several of the outcomes reported in Table 2, we tested the differential effects of Internet use with age. There was only one marginally significant interaction: Adults' stress increased more than teens' stress with more Internet use $(\mathrm{p}<.10)$.

\section{Study 2: A longitudinal study of computer and television purchasers}

Study 2 is a replication of the original HomeNet research design in a sample of households that had recently purchased new home technology_either a computer or TV. We added controls to the design and new measures. First, we attempted to manipulate Internet use to create a true experiment, with participants randomly assigned to condition. We recruited households who recently bought a new home computer and randomly offered half free Internet service; households in the control condition received an equivalent amount of money $(\$ 225)$ to participate. Unfortunately, this experimental procedure failed when, by the end of 12 months, $83 \%$ of the control households obtained Internet access on their own (versus $95 \%$ of the experimental households who took advantage of free Internet service). Because this attempt to conduct a true experiment failed, we combined the groups for analyses of the effects of using the Internet.

Another design change was to add a comparison group-recent purchasers of a new television set. Study 1 had only compared heavier and lighter users of the Internet, all of whom had access to it. The addition of a TV-purchaser comparison group in Study 2 (of whom just $29 \%$ obtained Internet access after 12 months) provides a sample that was unlikely to use the Internet and helps to rule out explanations of change based on external events. In analyses of the effects of Internet use, we included participants from the television purchaser group, but 
controlled for sample selection bias by creating a dummy variable indicating whether participants were recruited for buying a television or computer.

We also increased the number of dependent variables, to examine the generalizability of the effects of using the Internet across outcomes and measures. The original study contained four measures of personal social involvement and three of psychological well-being. We added measures of personal social involvement (spending time with family and friends, use of the telephone, perceived closeness to a random sample from of the respondents' social networks). In response to Putnam's (2000) concerns that the Internet might undercut community participation as well as interpersonal contact, we added measures of involvement with and attitudes toward, the community at large. To measure psychological well-being, we added scales measuring the experience of negative and positive affect, perceived time pressure, and self-esteem. Because the Internet is a source of information as well as social contact, we added knowledge tests and a scale to measure computing skill. To test whether the distance-minimizing properties of the Internet blur traditional distinctions between geographically close and distant regions, our measures of social involvement and knowledge differentiated between these, for example, asking separately about local and distant social circles and about knowledge of the Pittsburgh region and broader areas.

Finally, we extended the HomeNet study conceptually by examining the differential effects of individual differences in extraversion and perceived social support on the effects of Internet use. Extraversion is the tendency to like people, to be outgoing, and to enjoy social interaction; it is a highly stable personality trait, predictive of social support, social integration, well-being, and positive life events (e.g., Von Dras \& Siegler, 1997; Magnus, Diener, Fujita, Payot, 1993). The perception of social support refers to feelings that others are available to 
provide comfort, esteem, assistance, and information or advice; perceived social support buffers the effects of stress (e.g., Cohen, 1988).

We offer two opposing models of the relationship between extraversion and social support and Internet use. A "rich get richer" model predicts that those who are highly sociable and have existing social support will get more social benefit from using the Internet. Highly sociable people may reach out to others on the Internet and be especially likely to use the Internet for communication. Those who already have social support can use the Internet to reinforce ties with those in their support networks. If so, these groups would gain more social involvement and well-being from using the Internet than those who are introverted or have limited networks. They can gain these benefits both by adding members to their social networks and by strengthening existing ties.

By contrast, a "social compensation" model predicts that those who are introverted or lack social support would profit most from using the Internet. People with fewer social resources could use the new communication opportunities online to form connections with people and obtain supportive communications and useful information otherwise missing locally (see McKenna \& Bargh, 1998). At the same time, for those who already have satisfactory relationships, using the Internet might interfere with their real-world relationships, if they swap, strong real world ties for weaker ones online. Analogous to the finding that cancer patients with emotionally-supportive spouses can be harmed by participating in peer-discussion support groups (Helgeson, Cohen, Schulz, \& Yasko, 2000), it is possible that people with strong local relationships might turn away from family and friends if they used the Internet for social interaction. 


\section{Method}

Sample. We recruited participants through advertisements placed in local newspapers, soliciting people for a study of household technology who purchased a new computer or new television within the previous six months. We obtained agreement from all adults and children in the family above age 10 to complete surveys. Half of the computer purchaser households were randomly offered free Internet access to participate in the study; the other participants were offered payments to complete surveys. After the initial telephone contact, we mailed consent forms and pretest surveys with return envelopes. Unlike the procedures used in Study 1, we did not encourage Internet use or provide technology support.

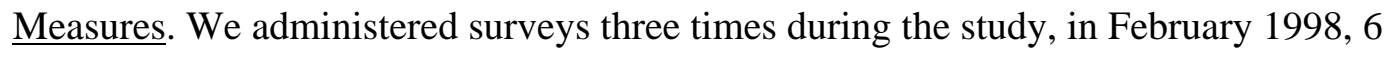
months later, and a year later, February 1999. Because we had automated measures of Internet usage only for the group randomly given Internet access, our main independent variable is an index of self-reported Internet use (e.g.," I use the world wide web very frequently"; "Time per day spent using email"; "Frequency per month of using a computer at home". The full text of for unpublished measures is available at http://HomeNet.hcii.cs.cmu.edu/progress/research.html.) Within the group randomly given Internet access, the Pearson correlations between the self report index of Internet use and the automated count of the number of sessions logged into the Internet in the 8 weeks surrounding the questionnaires was moderate $(r(112)=.55$ at Time 2 and $r(104)=.42$ at Time 3). These correlations reflect moderate validity of the self-report measure, although they are far from perfect because there is error in both the self-reports and in the server data (e.g., the usage records do not include Internet use at work and include cases where one family member uses another's account). 
We used self-report measures to assess demographic characteristics of the participants, and measures from the original HomeNet study, including perceived social support (Cohen et al., 1984), size of local and distant social circles, and time talking with other family members. We used the same measure of extraversion (Bendig, 1962). We added new measures of anomie (Srole, 1956), trust in people (Rosenberg, 1957, revised from Survey Research Center, 1969), community involvement (adapted from Mowday and Speers' 1979 measure of organizational commitment; e.g., I spend a lot of time participating in community activities.; I feel part of the community in Pittsburgh), and intentions to stay in the Pittsburgh area ("Even if I had a chance to move to another city, I would very much want to stay in the Pittsburgh area"). We also assessed respondents' relationships with specific family and friends by asking them "How close do you feel?" to five individuals living in the Pittsburgh area and five living outside of the area who were closest to them in age. Participants described closeness to each nominee 5-point Likert scales.

To assess well-being, we again used the CES-D to measure depressive symptoms (Radloff, 1977), the daily life stresses scale (Kanner, Coyne, Schaefer, \& Lazarus, 1981), and the UCLA Loneliness Scale (Russell, Peplau, \& Cutrona, 1980) from the original HomeNet study. We added measures of self-esteem (Heatherton \& Polivy, 1991), positive and negative affect (Watson, Clark, \& Tellegen, 1988), perceived time pressure (adapted from Kraut \& Attewell, 1997) and physical health (subscale from the SF-36; Ware, Snow, Kosinski, \& Gandek, 1993). Finally, because the Internet is a source of information as well as communication, we added measures of knowledge. We included a self-report measure of skill using computers, expanded from the original HomeNet study (e.g., "I am very skilled at using computers"; "I don't know much about using computers", (R)). We also added a test of knowledge, including 
multiple choice items on national current events, Pittsburgh current events, and general knowledge from a high school equivalency test (Research \& Education Association, 1996). The knowledge test contained different items at different time periods.

Analyses. Data come from 216 households. Of the 446 individuals who were eligible to be in the sample, $96 \%$ completed survey $1,83 \%$ completed survey 2 and $83.2 \%$ completed survey 3. Analyses are based on 406 respondents (91\% of the original sample) who completed at least two surveys. The analyses were similar to those for Study 1. We used Stata's xtreg procedure, with participant as a random effect, (StataCorp, 2001) to analyze the panel design. In the Study 2 models, social involvement, well-being, and knowledge outcomes at the second and third time period were regressed on self-reported Internet use during that period, controlling for demographic characteristics and the lagged dependent variables. The models control for whether the respondent came from the TV purchaser or computer purchaser sub-sample and whether the dependent variables were collected at the second or third time period. To test whether levels of extraversion and social support moderated the effects of using the Internet, we included the main effects for the Bendig (1962) measure of extraversion and Cohen et al.'s (1984) measure of social support and the interaction of these variables with Internet use. We included adult status, gender, race, education and household income as demographic controls. Because teenagers use the Internet quite differently from adults, we also included the interaction of generation with Internet use.

$\underline{\text { Results }}$

Table 2 shows scale reliabilities and descriptive statistics for variables in the sample, averaged over the three time periods. A table of correlations is available at http://HomeNet.hcii.cs.cmu.edu/progress/research.html. 
Effects on interpersonal and community social involvement. Models testing the effects of using the Internet on interpersonal communication and community involvement are shown in Tables 3 and 4, respectively. The main effects of Internet use on these measures of social involvement were generally positive. As Table 3 shows, participants who used the Internet more had larger increases in the sizes of their local social circle $(\mathrm{p}<.01)$ and distant social circle $(\mathrm{p}<$ $.01)$ and their face-to-face interaction with friends and family increased $(\mathrm{p}<.05)$. As Table 4 shows, they also reported becoming more involved in community activities $(\underline{p}<.10)$ and felt greater trust in people $(\mathrm{p}<.05)$. The only significant reversal to the positive trend is that those who used the Internet more became less committed to living in the Pittsburgh area $(\mathrm{p}<.05)$.

The interaction with extraversion shows that the association of Internet use with changes in community involvement was positive for extraverts and negative for introverts. Figure 1a illustrates these effects. Holding constant respondents' prior community involvement, extraverts who used the Internet extensively reported more community involvement than those who rarely used it; on the other hand, introverts who used the Internet extensively reported less community involvement than those who rarely used it. Interactions of Internet use with social support show that Internet use was associated with larger increases in family communication for those who initially had more social support. Each of these interaction effects supports the "rich get richer" hypothesis.

Finally, interactions of age with Internet use suggest different positive effects for adults and teens. Teens, as compared with adults, increased their social support and family communication with more Internet use, whereas adults increased their face-to-face interaction with family and friends and their closeness to distant relatives and friends with more Internet use. 
Insert Table 3 and 4 and Figure 1 about here

Effects on psychological and physical well-being. Table 5 shows the effects of Internet use on psychological well-being. These results are mixed, showing that, overall, both stress and positive affect increased with Internet use. The several interactions of Internet use with extraversion indicate that Internet use was associated with better outcomes for extraverts and worse outcomes for introverts. In particular, extraverts who used the Internet more reported increased well-being, including decreased levels of loneliness, decreased negative affect, decreased time pressure, and increased self-esteem. In contrast, these same variables showed declines in well-being for introverts. Figure $1 \mathrm{~b}$ illustrates these effects . Holding constant prior loneliness, extraverts who used the Internet extensively were less loneliness than those who rarely used it, while introverts who used the Internet extensively were more loneliness than those who rarely used it. There were no interactions with social support or with age, and no effects on measures of physical health (not shown in the table).

Insert Tables 5 and 6 about Here

Effects on skill and knowledge. Table 6 shows the effects of Internet use on self-reported computer skill and multiple choices tests of world knowledge. Computer skill increased with more Internet use $(\underline{p}<.001)$; this increase was larger among those with more social support $(\underline{p}<$ .05). Knowledge of general knowledge (not shown in the table) and national current events did not change with Internet use. In contrast, those who used the Internet more became less knowledgeable about the local Pittsburgh area $(\mathrm{p}<.05)$. 
Different uses of the Internet. Because the way people choose to use the Internet could strongly influence its effects, we asked participants to report how often they used the Internet for various purposes. We conducted an exploratory factor analysis of these items to create four scales reflecting different uses of the Internet: (a) for communication with friends and family; (b) for acquiring information for school, work, news, and other instrumental purposes such as shopping; (c) for entertainment such as playing games, downloading music, and escape and (d) for meeting new people and socializing in chat rooms. These uses of the Internet were moderately interrelated (mean $\underline{r}=.51$ ). Using the Internet for communication with family and friends $(\underline{r}=.69)$ and for information $(\underline{r}=.62)$ had the highest association with the Internet use index in reported in Table 2, followed by use for entertainment $(\underline{r}=.51)$ and meeting new people $(\underline{r}=.38)$. Those with more extraversion were more likely than those with less extraversion to use the Internet to keep up with friends and family $(\underline{r}=.10, \underline{p}<.05)$ and to meet new people online and frequent chat rooms $(\underline{\mathrm{r}}=.12, \underline{\mathrm{p}}<.05)$, but the associations were weak. Those with stronger initial social support were less likely than those with weaker support to use the Internet to meet new people or use chat rooms online $(\underline{r}=.11, \underline{p}<.05)$ or for entertainment $(\underline{r}=-.14, \underline{p}<.05)$. Adults were more likely than teens to use the Internet for meeting new people $(\underline{r}=-.41, \underline{p}<.001)$ and for entertainment $(\underline{\mathrm{r}}=-.29, \underline{\mathrm{p}}<.001)$.

To test whether particular ways of using the Internet were more beneficial than others, we conducted a mediation analysis, by adding the measures of specific Internet use to the models in Tables 3-6. These additions did not significantly affect the interactions between overall Internet use and extraversion or social support. 


\section{Discussion}

The original HomeNet sample began using the Internet in 1995 or 1996. Our follow-up of participants remaining in the sample in 1998 showed that most of negative outcomes initially associated with use of the Internet dissipated, except for its association with increased stress. The statistical interactions of loneliness and depressive symptoms with time period suggest that use of the Internet led to negative outcomes during the first phase of the study and more positive outcomes later.

In Study 2, conducted from 1998 to 1999, more use of the Internet was associated with positive outcomes over a broad range of dependent variables measuring social involvement and psychological well-being-local and distant social circles, face-to-face communication, community involvement, trust in people, positive affect, and unsurprisingly, computer skill. On the other hand, heavier Internet use was again associated with increases in stress. In addition, it was associated with declines in local knowledge, and declines in the desire to live in the local area, suggesting lowered commitment to the local area.

Having more social resources amplified the benefits that people got from using the Internet on several dependent variables. Among extraverts, using the Internet was associated with increases in community involvement and self-esteem, and declines in loneliness, negative affect, and time pressure; it was associated with the reverse for introverts. Similarly, among people with more rather than less social support, using the Internet was associated with more family communication and greater increases in computer skill. Adults and teens gained somewhat different benefits from more Internet use, with adults more likely to increase their face-to-face interactions locally and their closeness to geographically distant relatives and friends. 
What accounts for the differences between the original HomeNet research, showing generally negative consequences of using the Internet, and the follow-ups, showing generally positive consequences? Maturation of participants between the early and late phases of Study 1, differences in samples between Studies 1 and 2, and changes in the Internet itself are all potential explanations for this shift in results. Although our research cannot definitely choose among these explanations, a change in the nature of the Internet is the most parsimonious explanation.

Maturation of participants and changes in the way they used the Internet could potentially account for the shift in results between the early and later phases of Study 1. For example, as the novelty of using the Internet wore off, participants may have jettisoned unrewarding Internet activities and adopted or increased their use of more personally rewarding ones. However, the first phase of Study 1, with its negative outcomes, occurred during participants' first year on line. Study 2, with its positive outcomes, also occurred during a one-year period, when most participants' were new to the Internet. Thus, while maturation could account for differences between the early and late phases of Study 1, it cannot account for differences between Studies 1 and 2 .

Participants in Studies 1and 2 came from separate opportunity samples. These sample differences make comparisons between the two studies problematic and could potentially account for differences in results between them. For example, the original sample included a larger proportion of teens and minorities. Although teenagers and adults gained somewhat different benefits from using the Internet, teenagers did not fare worse overall than adults from using the Internet. Similarly, supplementary analyses (not shown in Tables 3-6) do not reveal racial differences in outcomes that can account for difference between the two studies. Participants in Study 1 had more social support and were more extraverted than those in Study 2, 
probably because they were recruited from families with organizational memberships. However, the statistical interactions with extraversion and social support reported in Study 2 would lead one to expect that outcomes would be more positive in Study 1 than Study 2, but this was not the case. While other, unmeasured differences in the samples might account for the differences in results between Study 1 and Study 2, differences in age, race, and social resources do not appear to do so.

The similarity of findings comparing the early and later phases of Study 1 and comparing Studies 1 and 2 suggest that changes in the Internet environment itself might be more important to understanding the observed effects than maturation or differences between samples. Simply put, the Internet may have become a more hospitable place over time. From 1995 to 1998, the number of Americans with access to the Internet at home more than quadrupled. As a result, many more of participants' close family and friends were likely to have obtained Internet access. Similarly, the services offered online changed over this period, increasing the ease with which people could communicate with their strong ties. For example, new communication services, such as American Online's instant messaging allow users to subscribe to a list of family and friends and be notified when members of their "buddy lists" came online. In addition to these changes to the online social environment, over the span of this research, the Internet provided a richer supply of information, with more news, health, financial, hobby, work, community, and consumer information available. It began to support financial and commercial transactions. Together, these changes could have promoted better integration of participants' online behavior with the rest of their lives.

Our finding from Study 2, that extraverts and those with more support benefited more from their Internet use, is consistent with this idea. That is, the Internet may be more beneficial 
to individuals to the extent they can leverage its opportunities to enhance their everyday social lives. Those who are already effective in using social resources in the world are likely to be well positioned to take advantage of a powerful new technology like the Internet.

Research shows that people can form strong social bonds online, and relationships formed online can carry over to the off-line world (e.g., Parks \& Roberts, 1998; McKenna, Green, \& Gleason, this issue). However, research also suggests that strong relationships developed online are comparatively rare. Most studies show that people use the Internet more to keep up with relationships formed off line than to form new ones (e.g, Kraut et al, 1996; Pew Internet and American Life Project, 2000). In addition, online relationships are weaker on average than those formed and maintained off-line (e.g., Cummings, Butler, \& Kraut, in press; Gross, Juvonen, \& Gable, this issue). Gross, Juvonen, and Gable (this issue) also report that adolescents who feel socially anxious and/or lonely are especially likely to communicate online with people with whom they do not feel close. Thus one would expect that a diet filled with online relationships would be harmful to the social and psychology health of Internet users. Fortunately, people don't seem to use the Internet this way. Rather they mingle their online and offline worlds, using the Internet to keep up with people from their off-line lives and calling and visiting people they initially met online (Kraut et al, 1996; McKenna et al, this issue).

Although the impact of using the Internet across the two studies was generally positive, some negative outcomes remained. Across both studies, as people used the Internet more, they reported increases in daily life stress and hassles. Supplementary analyses did not identify any single stressor that occurred more frequently with Internet use, even though the cumulative increase with Internet use was statistically significant. One explanation is that the time spent 
online leaves less for many other activities, and that this time drought may lead to a generalized perception of stress.

In addition, to increases in stress, heavier Internet use was also associated with declining commitment to living in the local area and less knowledge about it. These declines may come about because the Internet makes available an abundance of online information (and social relationships) outside of the local area. Unlike regional newspapers, for example, the Internet makes news about distant cities as accessible as news about ones hometown.

The mechanisms by which the Internet has its impact on social involvement and psychological well-being remain unclear. One possibility is that the effects of using the Internet depend upon what people do online. For example, one might expect that interpersonal communication with friends and family would have more beneficial effects than using the Internet for downloading music, playing computer games or communicating with strangers. Another possibility is that all uses of the Internet are equivalent in this regard, and that the important factor is not how people use the Internet, but what they give up to spend time online. Thus the effects of using the Internet might be very different if it substituted for time spent watching TV or time spent conversing with close friends. No research to date, however, including our own, can distinguish between these two possibilities. Our own attempts to identify the unique effects of using the Internet for different functions were unsuccessful. Self-report measures may be too insensitive to track true differences in use.

Understanding the mechanisms for the Internet's impact is essential for informing private, commercial, and public policy decisions. People need better information to know whether to ration their time online or to decide which uses of the Internet are in their long-term interests. As experience with television suggests, enjoyable uses of new technology may be 
harmful in the long term (e.g., Huston et al, 1992; Putnam, 2000). Service providers need to decide what applications to offer online. School and libraries need to decide whether to offer email and chat capabilities along with their information-oriented services.

Experiment are a standard way to assess the impact of an intervention. While laboratory experiment can identify short-term consequences of Internet use, they are too limited to illuminate how the Internet affects slowly emerging phenomena, such as social relationships, community commitment, or psychological well-being (Rabby \& Walther, In press), . Unfortunately, it is probably late in the evolution of the Internet to carry out true long-term experiments, at least in North America. We tried to conduct such an experiment on Internet use for Study 2, but in less than 12 months, $83 \%$ of the households in the control group had acquired Internet access on their own.

Nonetheless, researchers should continue to attempt to discern how using the Internet is affecting people's lives with the best designs possible. Although cross-sectional designs are most common in research on the impact of the Internet (e.g., Cole, 2000; Parks, \& Roberts, 19981; The Pew Internet \& American Life Project, 2000; Riphagen \& Kanfer, 1997), they cannot distinguish pre-existing differences among people who use the Internet from consequences of using it. Therefore, we believe longitudinal designs are essential to understanding the effects of Internet use and the differences in these effects as the Internet changes. In addition, we need better and more detailed descriptions of how people spend their time, both online and off, to relate these detailed descriptions to changes in important domains of life. The diary measures used by Gross, Juvonen, and Gable, (this issue) is a step in this direction. 


\section{References}

Bendig, A. W. (1962). The Pittsburgh scales of social extraversion, introversion and emotionality. The Journal of Psychology, 53, 199-209.

Cohen J. \& Cohen, P. (1983). Applied multiple regression/correlation analysis for the behavioral sciences. Hillsdale, NJ: Lawrence Erlbaum Associates.

Cohen, S., \& Wills, T. A. (1985). Stress, social support, and the buffering hypothesis. Psychological Bulletin, 98, 310-357.

Cohen, S., Mermelstein, R., Kamarck, T., \& Hoberman, H. (1984). Measuring the functional components of social support. In I.G. Sarason \& B. R. Sarason (Eds.), Social support: Theory, research and applications (pp. 73-94). The Hague, Holland: Martines Niijhoff.

Cole, J. (2000). Surveying the digital future: The UCLA Internet report. Downloaded from http://WWW.CCP.UCLA.EDU/pages/internet-report.asp. November 17, 2000.

Cummings, J., Butler, B. \& Kraut, R. (In press). The quality of online social relationships. Communications of the ACM.

Diener, E., Suh, E. M., Lucas, R. E., \& Smith, H. (1999). Subjective well-being: Three decades of progress. Psychological Bulletin, 125, 276-302.

Fischer, C. S. (1992). America calling. Berkeley, CA: University of California Press.

Heatherton, T. F., \& Polivy, J. (1991). Development and validation of a scale for measuring state self-esteem. Journal of Personality and Social Psychology, 60, 895-910.

Helgeson, V. S., Cohen, S., Schulz, R., \& Yasko, J. (2000). Group support interventions for people with cancer: Who benefits from what? Health Psychology, 19, 107-114.

Hiltz, S. R., \& Turoff, M. (1978). Network nation: Human communication via computer. Reading, MA: Addison Wesley. 
Huston, A.C., Donnerstein, E., Fairchild, H., Feshbach, N.D., Katz, P.A., Murray, J.P., Rubinstein, E.A., Wilcox, B., \& Zuckerman, D. (1992). Big world, small screen: The role of television in American society. Lincoln, NE: University of Nebraska Press.

Kanner, A. D., Coyne, J.C., Schaefer, C. \& Lazarus, R.S. (1981). Comparisons of two modes of stress measurement: Daily hassles and uplifts versus major life events, Journal of Behavioral Medicine, 4, 1-39.

Kiesler, S. Lundmark, V., Zdaniuk, B., Kraut, R. Scherlis, W. \& Mukhopadhyay, T. (2000). Troubles with the Internet: The dynamics of help at home. Human-Computer Interaction, 15(4), 223-352.

Kraut, R. E. \& Attewell, P. (1997). Media use in a global corporation: Electronic mail and organizational knowledge (pp. 323-342). In S. Kiesler (Ed.) Culture of the Internet. Mahwah, NJ: Erlbaum.

Kraut, R., Mukhopadhyay, T., Szczypula, J., Kiesler, S., \& Scherlis, B. (2000). Information and communication: Alternative uses of the Internet in households. Information Systems Research, 10, 287-303

Kraut, R. E., Patterson, M., Lundmark, V., Kiesler, S., Mukhopadhyay, T., \& Scherlis, W. (1998). Internet paradox: A social technology that reduces social involvement and psychological well-being? American Psychologist, 53, (9), 1017-1032.

Kraut, R., Scherlis, W., Mukhopadhyay, T., Manning, J., \& Kiesler, S. (1996.). The HomeNet field trial of residential Internet services. Communications of the ACM, 39, 55-63.

Magnus, K., Diener, E., Fujita, F., Payot, W. (1993). Extraversion and neuroticism as predictors of objective life events: A longitudinal analysis. Journal of Personality \& Social Psychology, 65, 1046-1053. 
McKenna, K.Y.A. \& Bargh, J. A. (1998). Coming out in the age of the Internet: Identity "demarginalization" through virtual group participation. Journal of Personality and Social Psychology, 75, 681-694.

McKenna, K.Y.A. \& Bargh, J. A. (2000). Plan 9 from cyberspace: The implications of the Internet for personality and social psychology. Personality and Social Psychology Review, 4, $57-75$.

Parks, M., \& Roberts, L. (1998). Making MOOsic: The development of personal relationships on line and a comparison to their off-line counterparts. Journal of Social and Personal Relationships, 15, 517-537.

The Pew Internet \& American Life Project (2000, May 10). Tracking online life: How women use the Internet to cultivate relationships with family and friends. Downloaded May 15, 2000. at http://www.pewinternet.org/reports/

Putnam, R. D. (2000). Bowling alone. NY: Simon \& Schuster.

Rabby, M., \& Walther, J. B. (in press). Computer-mediated communication impacts on relationship formation and maintenance. In D. Canary \& M. Dainton (Eds.), Maintaining relationships through communication: Relational, contextual, and cultural variations. Mahwah, NJ: Lawrence Erlbaum Associates.

Radloff, L. (1977). The CES-D Scale: A self-report depression scale for research in the general population, Applied Psychological Measurement, 1, 385-401.

Research \& Education Association (1996). The best test preparation for the GED (General Educational Development). Piscataway, N.J.: Author. 
Riphagen, J. \& Kanfer, A. (1997) How does e-mail affect our lives? Chapaign-Urbana Illinois: National Center for Supercomputing Applications. Retrieved October 15, 1999 from the World Wide Web: http://www.ncsa.uiuc.edu/edu/trg/e-mail/index.html

Rosenberg, M. (with the assistance of E.A. Suchman \& R.K. Goldsen) (1957). Occupations and values. Glencoe, Ill.: Free Press.

Russell, D., Peplau, L., \& Cutrona, C. (1980) The revised UCLA loneliness scale: Concurrent and discriminant validity evidence. Journal of Personality and Social Psychology, 39(3), $472-480$.

Shapiro, J. S. (1999). Loneliness: Paradox or artifact? The American Psychologist, 54(9), 782783.

Sproull, L. \& Kiesler, S. (1991). Connections: New ways of working in the networked organization. Cambridge, MA: MIT Press.

Srole, L. (1956). Social integration and certain corollaries. American Sociological Review, 21, 709-716.

StataCorp (2001). Stata Statistical Software: Release 7.0. College Station, TX: Stata Corporation. Survey Research Center (1969). 1964 election study. Ann Arbor, Michigan: Inter-University Consortium for Political Research, University of Michigan.

Thoits, P. (1983). Multiple identities and psychological well-being: A reformulation and test of the social isolation hypothesis. American Sociological Review, 48, 174-187.

Von Dras, D. D. \& Siegler, I. C. (1997). Stability in extraversion and aspects of social support at midlife. Journal of Personality \& Social Psychology, 72, 233-241

Ware, J.E., Snow, K.K., Kosinski, M., \& Gandek, B., SF-36 Health Survey: Manual and interpretation guide. Boston: Nimrod, 1993. 
Watson, D., Clark, L. A., \& Tellegen, A. (1988). Development and validation of brief measures of positive and negative affect: The PANAS scales. Journal of Personality and Social Psychology, 54, 1063-1070.

Wellman, Barry, Anabel Quan, James Witte \& Keith Hampton (2001). Does the Internet Increase, Decrease or Supplement Social Capital?: Social Networks, Participation, and Community Commitment. American Behavioral Scientist 45.

Wellman, B. \& Wortley, S. (1990). Different strokes for different folks: Community ties and social support. American Journal of Sociology, 96(3), 558-88.

Williams, A. W., Ware, J. E., \& Donald, C. A. (1981). A model of mental health, life events, and social supports applicable to general populations. Journal of Health and Social Behavior, 22, 324-33 
Table 1: Descriptive statistics for variables in Studies 1 and 2.

Variable

\begin{tabular}{|c|c|}
\hline \multirow{2}{*}{\multicolumn{2}{|c|}{ Adult ${ }^{\mathrm{a}}$}} \\
\hline & \\
\hline Male $^{\mathrm{a}}$ & \\
\hline White $^{\mathrm{a}}$ & \\
\hline Income $^{b}$ & \\
\hline Education $^{\mathrm{c}}$ & \\
\hline Computer sample $^{\mathrm{a}}$ & \\
\hline Extraversion ${ }^{g}$ & \\
\hline Social support ${ }^{\mathrm{g}}$ & \\
\hline Internet use $^{\mathrm{h}}$ & \\
\hline Local circle $(\log )^{\mathrm{d}}$ & \\
\hline Distant circle $(\log )^{e}$ & \\
\hline Family communication $(\log )$ & \\
\hline Face-to-face communicaton & \\
\hline Phone communicationf & \\
\hline Closeness near friends $\mathrm{s}^{\mathrm{g}}$ & \\
\hline Closeness distant friends $\mathrm{s}^{\mathrm{g}}$ & \\
\hline Community involvment $^{\mathrm{g}}$ & \\
\hline Stay in Pittsburgh ${ }^{\mathrm{g}}$ & \\
\hline Trust $^{\mathrm{g}}$ & \\
\hline Anomie $\mathrm{g}^{\mathrm{g}}$ & \\
\hline Stress $^{j}$ & \\
\hline Loneliness ${ }^{g}$ & \\
\hline Depression $^{\mathrm{i}}$ & \\
\hline Negative affect & \\
\hline Positive affect ${ }^{\mathrm{g}}$ & \\
\hline Time pressure ${ }^{\mathrm{g}}$ & \\
\hline Self-esteem ${ }^{g}$ & \\
\hline Computer skill $^{\mathrm{g}}$ & \\
\hline US knowledge & \\
\hline Local knowledge & \\
\hline
\end{tabular}

Study 2

\begin{tabular}{rrrrr}
\multicolumn{2}{c}{ Alpha } & \multicolumn{1}{l}{ Mean } & \multicolumn{1}{l}{ Std } & \multicolumn{1}{l}{ N } \\
& NA & .88 & .32 & 446 \\
& NA & .47 & .50 & 446 \\
& NA & .92 & .27 & 438 \\
& NA & 4.91 & 1.55 & 443 \\
& NA & 4.06 & 1.23 & 446 \\
& NA & .72 & .45 & 446 \\
& .80 & 3.22 & .65 & 389 \\
.81 & 3.80 & .54 & 389 \\
& .86 & .00 & .78 & 406 \\
& NA & 2.56 & .79 & 375 \\
NA & 2.21 & 1.05 & 361 \\
NA & 4.10 & 1.63 & 389 \\
& .55 & -.01 & 1.00 & 406 \\
& .83 & 4.69 & 1.15 & 387 \\
& NA & 3.54 & .76 & 434 \\
& NA & 2.94 & 1.10 & 286 \\
& .70 & 2.83 & .75 & 390 \\
& NA & 3.69 & 1.38 & 388 \\
& .74 & 3.17 & .83 & 391 \\
& .57 & 2.66 & .63 & 391 \\
.88 & .22 & .14 & 382 \\
& .75 & 2.10 & .66 & 389 \\
.88 & .53 & .47 & 389 \\
.88 & 1.67 & .64 & 390 \\
& .88 & 3.49 & .72 & 388 \\
& .82 & 3.02 & .76 & 390 \\
.85 & 3.70 & .62 & 389 \\
& .90 & 3.26 & .93 & 389 \\
& .41 & .71 & .33 & 388 \\
.34 & .68 & .26 & 388
\end{tabular}

Note: All variables are coded so that higher numbers indicate more of the variable.

${ }^{a}$ Dicotomous variable $(0 / 1)$

${ }^{\mathrm{b}} 6$ categories, from under $\$ 10,000$ to over $\$ 75.000$

${ }^{\mathrm{c}} 6$ categories, from less than 11th grade to graduate-level work

${ }^{\mathrm{d}}$ Truncated at 60 and logged

${ }^{\mathrm{e}}$ Truncated at 100 and logged

fSum of minutes communicating with other household members, logged

${ }^{\mathrm{g}} 5$-point Likert response scale, with endpoints 1 and 5, where 5 is highest score.

${ }^{\text {h}}$ Hours per week using the Internet (logged) in Study 1; Mean of standardized variables in Study 2 ${ }^{i} 4$-point Likert scales, with endpoint 0 and 3, where 3 is highest score.

${ }^{\mathrm{j}}$ Mean of dicotomous response scales (0/1)

${ }^{k}$ Proportion correct on multiple choice questions 
Table 2. Analysis of the original HomeNet study after 3 years $(\underline{\mathrm{n}}=208)$.

\begin{tabular}{|c|c|c|c|c|c|c|c|c|c|c|c|c|c|c|c|c|c|c|c|c|c|}
\hline \multirow[b]{2}{*}{ Independent variables } & \multicolumn{3}{|c|}{ Social Support $^{\mathrm{a}}$} & \multicolumn{3}{|c|}{$\begin{array}{c}\text { Local social } \\
\text { circle }^{b}\end{array}$} & \multicolumn{3}{|c|}{$\begin{array}{l}\text { Distant social } \\
\text { circle }^{c}\end{array}$} & \multicolumn{3}{|c|}{$\begin{array}{c}\text { Family } \\
\text { Communication } \\
(\log )^{\mathrm{d}}\end{array}$} & \multicolumn{3}{|c|}{ Stress $^{\mathrm{e}}$} & \multicolumn{3}{|c|}{ Depression $^{\mathrm{f}}$} & \multicolumn{3}{|c|}{ Loneliness $^{\mathrm{g}}$} \\
\hline & beta & se & p & beta & se & p & beta & se & p & beta & se & p & beta & se & $\underline{p}$ & beta & se & p & beta & se & $\underline{p}$ \\
\hline Intercept & 0.00 & 0.04 & & 3.76 & 3.37 & & 8.85 & 6.74 & & -0.03 & 0.05 & & 0.01 & 0.01 & & -0.01 & 0.03 & & 0.03 & 0.04 & \\
\hline Adult $(0=$ teen $; 1=$ adult $)$ & -0.13 & 0.09 & & -19.37 & 7.41 & $* *$ & -49.02 & 14.70 & $* * *$ & 0.34 & 0.11 & $* *$ & 0.00 & 0.02 & & -0.14 & 0.06 & * & 0.04 & 0.09 & \\
\hline Male $(0=$ female $; 1=$ male $)$ & -0.16 & 0.08 & * & -2.74 & 6.89 & & 6.57 & 13.70 & & -0.08 & 0.10 & & 0.00 & 0.02 & & 0.02 & 0.05 & & 0.27 & 0.08 & $* *$ \\
\hline Household income & 0.00 & 0.00 & & -0.20 & 0.15 & & 0.14 & 0.29 & & 0.00 & 0.00 & & 0.00 & 0.00 & $*$ & 0.00 & 0.00 & & 0.00 & 0.00 & \\
\hline White $(0=$ other $; 1=$ white $)$ & 0.15 & 0.09 & & -8.26 & 8.23 & & -6.74 & 16.38 & & 0.11 & 0.13 & & 0.04 & 0.02 & + & -0.14 & 0.07 & * & -0.22 & 0.10 & * \\
\hline Time period $^{\mathrm{h}}$ & 0.10 & 0.06 & & 0.97 & 2.52 & & -4.04 & 4.66 & & -0.34 & 0.10 & $* * *$ & 0.06 & 0.01 & $* * *$ & 0.01 & 0.04 & & 0.12 & 0.06 & + \\
\hline Stress $^{\mathrm{e}}$ & & & & & & & & & & & & & & & & 0.61 & 0.17 & $* * *$ & & & \\
\hline Extraversion $^{i}$ & 0.07 & 0.05 & & 1.04 & 2.74 & & -5.28 & 5.21 & & & & & & & & & & & & & \\
\hline Lagged dependent variable & 0.45 & 0.07 & $* * *$ & 0.21 & 0.06 & $* * *$ & 0.33 & 0.10 & $* * *$ & 0.37 & 0.08 & *** & 0.54 & 0.06 & $* * *$ & 0.18 & 0.06 & $* * *$ & 0.44 & 0.05 & $* * *$ \\
\hline Internet hours $(\log )$ & 0.02 & 0.05 & & -1.15 & 3.29 & & -5.14 & 6.27 & & 0.05 & 0.07 & & 0.03 & 0.01 & $*$ & -0.01 & 0.03 & & 0.00 & 0.05 & \\
\hline Internet $*$ period & 0.10 & 0.08 & & -0.37 & 3.06 & & 2.88 & 5.62 & & 0.16 & 0.12 & & -0.01 & 0.02 & & -0.13 & 0.05 & * & -0.21 & 0.08 & $* *$ \\
\hline Internet * adult & 0.06 & 0.09 & & 5.44 & 6.08 & & 7.52 & 11.57 & & -0.02 & 0.13 & & 0.04 & 0.02 & + & -0.08 & 0.06 & & -0.09 & 0.10 & \\
\hline$\underline{\mathrm{n}}$ & 189 & & & 189 & & & 187 & & & 177 & & & 195 & & & 187 & & & 186 & & \\
\hline$\underline{\mathrm{R}}^{2}$ & 0.29 & & & 0.26 & & & 0.17 & & & 0.15 & & & 0.46 & & & 0.20 & & & 0.36 & & \\
\hline
\end{tabular}

Note. $+\underline{p}<.10, * \mathrm{p}<.05, * * \mathrm{p}<.01, * * * \mathrm{p}<.001 ;$ Variables were centered before analyses..

${ }^{\mathrm{a} C}$ Cohen, et al, 1984; ${ }^{\mathrm{b}}$ Number kept up with monthly, living in the Pittsburgh area; ${ }^{\mathrm{c}}$ Number kept up with annually, living outside of the Pittsburgh area; ${ }^{\mathrm{d}} \log$ of the minutes communicating per day; ${ }^{\mathrm{e}}$ Kanner et al., 1981; ${ }^{\mathrm{f}}$ Radloff, $1977 ;{ }^{\mathrm{g}}$ Russell, et al, 1980; ${ }^{\mathrm{h}}$ Period 1 is 12-18 months, from 1995 or 1996 to 1997 and period 2 is from the first posttest in 1997 to the second posttest in $1998 .{ }^{i}$ Bendig, $1962 ;{ }^{j}$ the dependent variable measured approximately $12-18$ month previously. 
Table 3. Predicting interpersonal social involvement as a function of use of the Internet over time and individual difference variables. Study 2.

\begin{tabular}{|c|c|c|c|c|c|c|c|c|c|c|c|c|c|c|c|c|c|c|c|c|c|c|c|c|}
\hline \multirow[b]{2}{*}{ Independent variables } & \multicolumn{3}{|c|}{ Social support $^{\mathrm{a}}$} & \multicolumn{3}{|c|}{$\begin{array}{l}\text { Local social } \\
\text { circle }(\log )^{b}\end{array}$} & \multicolumn{3}{|c|}{$\begin{array}{l}\text { Distant social } \\
\text { circle }(\log )^{\mathrm{c}}\end{array}$} & \multicolumn{3}{|c|}{$\begin{array}{c}\text { Family } \\
\text { communication } \\
(\log )^{\mathrm{d}}\end{array}$} & \multicolumn{3}{|c|}{$\begin{array}{c}\text { Face-to-face } \\
\text { communication }^{\mathrm{e}}\end{array}$} & \multicolumn{3}{|c|}{$\begin{array}{c}\text { Phone } \\
\text { communication }^{\mathrm{e}}\end{array}$} & \multicolumn{3}{|c|}{$\begin{array}{l}\text { Closeness to } \\
\text { local friends }\end{array}$} & \multicolumn{3}{|c|}{\begin{tabular}{|c|} 
Closeness to \\
distant friends
\end{tabular}} \\
\hline & beta & se & $\mathrm{p}$ & beta & se & $\mathrm{p}$ & beta & se & $\mathrm{p}$ & beta & se & $\mathrm{P}$ & beta & se & $\mathrm{p}$ & beta & se & $\mathrm{p}$ & beta & se & $\mathrm{p}$ & beta & se & $\mathrm{p}$ \\
\hline Intercept & -0.01 & 0.02 & & -0.02 & 0.03 & & 0.01 & 0.04 & & 0.29 & 0.01 & $* * *$ & 0.02 & 0.03 & & -0.02 & 0.03 & & -0.01 & 0.06 & & -0.01 & 0.04 & \\
\hline Adult $(0=$ teen $; 1=$ adult $)$ & 0.18 & 0.05 & $* * *$ & -0.04 & 0.10 & & 0.31 & 0.12 & $*$ & 0.00 & 0.03 & & -0.55 & 0.11 & $* * *$ & 0.12 & 0.10 & & 0.27 & 0.17 & & 0.15 & 0.16 & \\
\hline Male $(0=$ female $; 1=$ male $)$ & -0.09 & 0.03 & $* *$ & 0.03 & 0.06 & & -0.08 & 0.07 & & -0.01 & 0.02 & & -0.19 & 0.07 & $* *$ & -0.30 & 0.07 & $* * *$ & -0.29 & 0.12 & $*$ & -0.02 & 0.09 & \\
\hline Household income & 0.15 & 0.06 & $*$ & 0.37 & 0.12 & $* *$ & 0.28 & 0.15 & + & -0.03 & 0.04 & & -0.11 & 0.13 & & -0.04 & 0.13 & & -0.41 & 0.25 & + & -0.16 & 0.20 & \\
\hline White $(0=$ other $; 1=$ white $)$ & 0.02 & 0.01 & $*$ & -0.01 & 0.02 & & 0.01 & 0.03 & & -0.01 & 0.01 & & -0.01 & 0.02 & & 0.03 & 0.02 & & -0.09 & 0.04 & $*$ & 0.01 & 0.03 & \\
\hline Education & 0.01 & 0.01 & & 0.00 & 0.03 & & 0.06 & 0.03 & + & 0.00 & 0.01 & & -0.04 & 0.03 & & -0.02 & 0.03 & & 0.00 & 0.05 & & -0.01 & 0.04 & \\
\hline $\begin{array}{c}\text { Computer sample } \\
(0=\text { no; } 1=\text { yes })\end{array}$ & 0.02 & 0.04 & & 0.12 & 0.07 & & 0.07 & 0.09 & & -0.01 & 0.02 & & -0.22 & 0.08 & $* *$ & -0.03 & 0.08 & & -0.10 & 0.13 & & -0.10 & 0.10 & \\
\hline $\begin{array}{l}\text { Time period }\left(0=1^{\text {st }} 6 \text { months; }\right. \\
\left.1=2^{\text {nd }} \text { six months }\right)\end{array}$ & 0.01 & 0.02 & & -0.05 & 0.04 & & -0.12 & 0.05 & $*$ & 0.00 & 0.01 & & 0.03 & 0.05 & & 0.08 & 0.04 & + & 0.00 & 0.00 & & -0.04 & 0.06 & \\
\hline Lagged dependent variable & 0.53 & 0.03 & $* * *$ & 0.33 & 0.04 & $* * *$ & 0.46 & 0.03 & $* * *$ & 3.86 & 0.04 & $* * *$ & 0.28 & 0.03 & $* * *$ & 0.50 & 0.03 & $* * *$ & -0.99 & 0.00 & $* * *$ & 0.50 & 0.04 & $* * *$ \\
\hline Extraversion $^{\mathrm{f}}$ & 0.15 & 0.03 & $* * *$ & 0.09 & 0.05 & $*$ & 0.09 & 0.06 & & 0.02 & 0.01 & & 0.14 & 0.05 & $* *$ & 0.16 & 0.05 & $* *$ & 0.00 & 0.00 & & 0.01 & 0.07 & \\
\hline Social support $^{\mathrm{a}}$ & & & & 0.17 & 0.05 & $* * *$ & 0.13 & 0.07 & + & 0.04 & 0.02 & $*$ & 0.28 & 0.07 & $* * *$ & 0.11 & 0.06 & + & 0.00 & 0.00 & & 0.30 & 0.08 & $* * *$ \\
\hline Internet use ${ }^{\mathrm{e}}$ & -0.01 & 0.02 & & 0.12 & 0.04 & $* *$ & 0.15 & 0.05 & $* *$ & 0.00 & 0.01 & & 0.09 & 0.04 & $*$ & 0.05 & 0.04 & & 0.00 & 0.00 & & 0.07 & 0.06 & \\
\hline Internet * extraversion & 0.01 & 0.03 & & 0.02 & 0.06 & & -0.05 & 0.07 & & -0.01 & 0.02 & & -0.02 & 0.07 & & 0.10 & 0.06 & & 0.00 & 0.00 & & 0.01 & 0.08 & \\
\hline Internet $*$ support & & & & 0.01 & 0.07 & & 0.02 & 0.09 & & 0.05 & 0.02 & $* *$ & -0.11 & 0.08 & & -0.08 & 0.07 & & 0.00 & 0.00 & & 0.15 & 0.10 & \\
\hline Internet $*$ adult & -0.11 & 0.06 & + & -0.13 & 0.11 & & -0.02 & 0.15 & & -0.06 & 0.03 & + & 0.30 & 0.13 & $*$ & 0.04 & 0.12 & & 0.00 & 0.00 & & 0.35 & 0.18 & $*$ \\
\hline$\underline{\mathrm{n}}$ & 406 & & & 385 & & & 365 & & & 373 & & & 406 & & & 391 & & & 351 & & & 285 & & \\
\hline$\underline{\mathrm{R}}^{2}$ & .51 & & & .42 & & & .47 & & & .95 & & & .31 & & & .51 & & & .16 & & & .44 & & \\
\hline
\end{tabular}

Note. $+\underline{p}<.10, * \underline{p}<.05, * * \underline{p}<.01, * * * \underline{p}<.001 ;$ Variables were centered before analyses.

${ }^{\mathrm{a} C}$ Cohen, et al, 1984; ${ }^{\mathrm{b}}$ Number kept up with monthly, living in the Pittsburgh area; ${ }^{\mathrm{c}}$ Number kept up with annually, living outside

of the Pittsburgh area; ${ }^{\mathrm{d}}$ Minutes communicating per day; ${ }^{\mathrm{e}}$ See Table $2 ;{ }^{\mathrm{f}}$ Bendig, 1962. 
Table 4. Predicting community social involvement as a function of use of the Internet

over time and individual difference variables. Study 2 .

\begin{tabular}{|c|c|c|c|c|c|c|c|c|c|c|c|c|}
\hline \multirow[b]{2}{*}{ Independent variables } & \multicolumn{3}{|c|}{$\begin{array}{l}\text { Community } \\
\text { involvement }^{\mathrm{a}}\end{array}$} & \multicolumn{3}{|c|}{$\begin{array}{c}\text { Stay in } \\
\text { Pittsburgh }^{\mathrm{b}}\end{array}$} & \multicolumn{3}{|c|}{ Trust $^{\mathrm{c}}$} & \multicolumn{3}{|c|}{ Anomie $^{d}$} \\
\hline & beta & se & $\mathrm{p}$ & beta & se & $\mathrm{p}$ & beta & se & $\mathrm{p}$ & beta & se & $\mathrm{p}$ \\
\hline Intercept & 0.00 & 0.02 & & -0.02 & 0.04 & & -0.01 & 0.02 & & 0.00 & 0.02 & \\
\hline Adult $(0=$ teen $; 1=$ adult $)$ & 0.11 & 0.07 & & -0.01 & 0.14 & & 0.30 & 0.08 & $* * *$ & -0.24 & 0.06 & $* * *$ \\
\hline Male $(0=$ female $; 1=$ male $)$ & -0.09 & 0.04 & $*$ & 0.11 & 0.08 & & -0.01 & 0.05 & & 0.07 & 0.04 & $*$ \\
\hline Household income & -0.10 & 0.09 & & 0.47 & 0.18 & $* *$ & 0.22 & 0.10 & $*$ & -0.12 & 0.08 & \\
\hline White $(0=$ other $; 1=$ white $)$ & -0.05 & 0.02 & $* *$ & -0.06 & 0.03 & $*$ & -0.02 & 0.02 & & -0.03 & 0.01 & + \\
\hline Education & 0.05 & 0.02 & $* *$ & 0.01 & 0.04 & & 0.04 & 0.02 & + & -0.03 & 0.02 & $*$ \\
\hline Computer sample $(0=$ no; $1=$ yes $)$ & 0.09 & 0.05 & + & 0.11 & 0.10 & & 0.07 & 0.06 & & -0.07 & 0.05 & \\
\hline $\begin{array}{l}\text { Time period }\left(0=1^{\text {st }} 6 \text { months; }\right. \\
\left.1=2^{\text {nd }} \text { six months }\right)\end{array}$ & 0.01 & 0.04 & & -0.07 & 0.06 & & -0.01 & 0.04 & & 0.04 & 0.03 & \\
\hline Lagged dependent variable & 0.51 & 0.03 & $* * *$ & 0.55 & 0.03 & $* * *$ & 0.51 & 0.03 & $* * *$ & 0.43 & 0.03 & $* * *$ \\
\hline Extraversion $^{\mathrm{f}}$ & 0.17 & 0.04 & $* * *$ & 0.13 & 0.07 & $*$ & 0.07 & 0.04 & + & -0.06 & 0.03 & + \\
\hline Social support $^{\mathrm{g}}$ & 0.17 & 0.04 & $* * *$ & 0.19 & 0.08 & $*$ & 0.21 & 0.05 & $* * *$ & -0.16 & 0.04 & $* * *$ \\
\hline Internet use ${ }^{\mathrm{e}}$ & 0.05 & 0.03 & + & -0.13 & 0.06 & $*$ & 0.07 & 0.03 & $*$ & -0.01 & 0.03 & \\
\hline Internet $*$ extraversion & 0.10 & 0.05 & $*$ & 0.09 & 0.09 & & 0.00 & 0.05 & & -0.01 & 0.04 & \\
\hline Internet $*$ support & 0.02 & 0.05 & & -0.08 & 0.10 & & 0.02 & 0.06 & & 0.02 & 0.05 & \\
\hline Internet $*$ adult & -0.01 & .09 & & 0.10 & 0.17 & & -0.12 & 0.10 & & -0.04 & 0.08 & \\
\hline$\underline{\mathrm{n}}$ & 403 & & & 402 & & & 405 & & & 405 & & \\
\hline$\underline{\mathrm{R}}^{2}$ & .50 & & & .49 & & & .48 & & & .47 & & \\
\hline
\end{tabular}

Note. $+\mathrm{p}<.10, * \mathrm{p}<.05, * * \mathrm{p}<.01, * * * \mathrm{p}<.001 ;$ Variables were centered before analyses.

${ }^{\mathrm{a}}$ see Table 2; ${ }^{\mathrm{b}}$ see Table 2; ${ }^{\mathrm{c}}$ Srole, $1956 ;{ }^{\mathrm{d}}$ Rosenberg, $1957 ;{ }^{\mathrm{e}}$ Bendig, 1962; ${ }^{\mathrm{f}}$ Cohen et al, 1984 
Table 5. Predicting psychological well being as a function of use of the Internet over time and individual difference variables.

Study 2.

\begin{tabular}{|c|c|c|c|c|c|c|c|c|c|c|c|c|c|c|c|c|c|c|c|c|c|}
\hline \multirow[b]{2}{*}{ Independent variables } & \multicolumn{3}{|c|}{ Stress $^{\mathrm{a}}$} & \multicolumn{3}{|c|}{ Loneliness $^{\mathrm{b}}$} & \multicolumn{3}{|c|}{ Depression $^{c}$} & \multicolumn{3}{|c|}{ Negative affect $^{d}$} & \multicolumn{3}{|c|}{ Positive affect ${ }^{\mathrm{e}}$} & \multicolumn{3}{|c|}{ Time pressure $^{f}$} & \multicolumn{3}{|c|}{ Self-esteem ${ }^{\mathrm{g}}$} \\
\hline & beta & se & $\mathrm{p}$ & beta & se & $\mathrm{p}$ & beta & se & $\mathrm{p}$ & beta & se & $\mathrm{p}$ & beta & se & $\mathrm{p}$ & beta & se & $\mathrm{p}$ & beta & se & $\mathrm{p}$ \\
\hline Intercept & 0.00 & 0.00 & & 0.00 & 0.02 & & 0.01 & 0.01 & & 0.01 & 0.02 & & 0.00 & 0.02 & & 0.00 & 0.02 & & -0.01 & 0.02 & \\
\hline Adult $(0=$ teen $; 1=$ adult $)$ & 0.04 & 0.02 & $* *$ & 0.08 & 0.06 & & 0.01 & 0.05 & & -0.12 & 0.07 & + & 0.05 & 0.08 & & 0.23 & 0.09 & $* *$ & 0.06 & 0.05 & \\
\hline Male $(0=$ female $; 1=$ male $)$ & -0.01 & 0.01 & & -0.01 & 0.03 & & 0.02 & 0.03 & & -0.02 & 0.04 & & 0.07 & 0.05 & & -0.18 & 0.05 & $* * *$ & 0.11 & 0.03 & $* * *$ \\
\hline Household income & 0.00 & 0.02 & & -0.10 & 0.07 & & 0.01 & 0.06 & & -0.03 & 0.09 & & -0.15 & 0.09 & + & 0.12 & 0.10 & & -0.01 & 0.07 & \\
\hline White $(0=$ other $; 1=$ white $)$ & 0.00 & 0.00 & & -0.01 & 0.01 & & -0.02 & 0.01 & + & -0.03 & 0.02 & $*$ & 0.02 & 0.02 & & 0.03 & 0.02 & & 0.01 & 0.01 & \\
\hline Education & 0.01 & 0.00 & & 0.01 & 0.02 & & -0.01 & 0.01 & & 0.03 & 0.02 & & 0.00 & 0.02 & & -0.02 & 0.02 & & -0.01 & 0.01 & \\
\hline $\begin{array}{l}\text { Computer sample } \\
(0=\text { no; } 1=\text { yes })\end{array}$ & -0.02 & 0.01 & + & -0.06 & 0.04 & & -0.03 & 0.04 & & -0.08 & 0.05 & & -0.02 & 0.06 & & -0.03 & 0.06 & & 0.07 & 0.04 & + \\
\hline $\begin{array}{l}\text { Time period }\left(0=1^{\text {st }} 6 \text { months; }\right. \\
\left.1=2^{\text {nd }} \text { six months }\right)\end{array}$ & 0.01 & 0.01 & & -0.04 & 0.03 & & -0.04 & 0.02 & + & -0.04 & 0.03 & & 0.07 & 0.03 & $*$ & -0.06 & 0.04 & + & 0.03 & 0.02 & \\
\hline Lagged dependent variable & 0.54 & 0.03 & $* * *$ & 0.27 & 0.03 & $* * *$ & 0.48 & 0.03 & $* * *$ & 0.39 & 0.03 & $* * *$ & 0.32 & 0.03 & $* * *$ & 0.41 & 0.03 & $* * *$ & 0.58 & 0.03 & $* * *$ \\
\hline Extraversion $^{\mathrm{f}}$ & 0.00 & 0.01 & & -0.21 & 0.03 & $* * *$ & 0.03 & 0.02 & & 0.01 & 0.04 & & 0.09 & 0.04 & $*$ & -0.15 & 0.04 & $* * *$ & 0.05 & 0.03 & + \\
\hline Social support $^{\mathrm{g}}$ & -0.02 & 0.01 & $*$ & -0.59 & 0.04 & $* * *$ & -0.21 & 0.03 & $* * *$ & -0.23 & 0.04 & $* * *$ & 0.41 & 0.05 & $* * *$ & -0.12 & 0.05 & $*$ & 0.28 & 0.03 & $* * *$ \\
\hline Internet use ${ }^{\mathrm{e}}$ & 0.01 & 0.01 & $*$ & 0.03 & 0.02 & & 0.01 & 0.02 & & 0.04 & 0.03 & & 0.14 & 0.03 & $* * *$ & 0.05 & 0.03 & & 0.02 & 0.02 & \\
\hline Internet $*$ extraversion & -0.01 & 0.01 & & -0.08 & 0.03 & $*$ & -0.05 & 0.03 & & -0.12 & 0.04 & $* *$ & 0.04 & 0.05 & & -0.14 & 0.05 & $* *$ & 0.09 & 0.03 & $* *$ \\
\hline Internet $*$ support & 0.01 & 0.01 & & 0.01 & 0.04 & & 0.01 & 0.04 & & -0.08 & 0.05 & & -0.08 & 0.06 & & 0.06 & 0.06 & & 0.04 & 0.04 & \\
\hline Internet $*$ adult & -0.02 & 0.02 & & -0.10 & 0.07 & & -0.09 & 0.06 & & -0.13 & 0.09 & & 0.10 & 0.09 & & -0.06 & 0.10 & & 0.01 & 0.07 & \\
\hline$\underline{\mathrm{n}}$ & 398 & & & & 406 & & & 405 & & & 405 & & & 405 & & & 406 & & & 406 & \\
\hline$\underline{\mathrm{R}}^{2}$ & .51 & & & & .66 & & & .48 & & & .40 & & & .43 & & & .42 & & & .63 & \\
\hline
\end{tabular}

Note. $+\underline{p}<.10, * \mathrm{p}<.05, * * \mathrm{p}<.01, * * * \mathrm{p}<.001 ;$ Variables were centered before analyses.

${ }^{\mathrm{a}}$ Kanner, Coyne, Schaefer, \& Lazarus, 1981; ${ }^{\mathrm{b}}$ Russell, Peplau, \& Cutrona, 1980; ${ }^{\mathrm{c}}$ Radloff, 1977; ${ }^{\mathrm{d}}$ Watson, Clark, \& Tellegen,

1988; ${ }^{\mathrm{e}}$ Watson, et al, 1988; ${ }^{\mathrm{f}}$ see Table 2; ${ }^{\mathrm{g}}$ Heatherton \& Polivy, 1991; ${ }^{\mathrm{h}}$ Bendig, 1962; ${ }^{\mathrm{i}}$ Cohen et al, 1984 
Table 6. Predicting knowledge as a function of use of the Internet over time and individual difference variables. Study 2.

\begin{tabular}{|c|c|c|c|c|c|c|c|c|c|}
\hline \multirow[b]{2}{*}{ Independent variables } & \multicolumn{3}{|c|}{ Computer skill $^{\mathrm{a}}$} & \multicolumn{3}{|c|}{ U. S. knowledge ${ }^{\mathrm{a}}$} & \multicolumn{3}{|c|}{ Local knowledge $^{\mathrm{a}}$} \\
\hline & beta & se & $\mathrm{p}$ & beta & se & $\underline{p}$ & beta & se & $\underline{\mathrm{p}}$ \\
\hline Intercept & 0.02 & 0.02 & & 0.00 & 0.01 & & 0.00 & 0.01 & \\
\hline Adult $(0=$ teen $; 1=$ adult $)$ & -0.11 & 0.07 & & 0.18 & 0.04 & $* * *$ & 0.13 & 0.03 & $* * *$ \\
\hline Male $(0=$ female $; 1=$ male $)$ & 0.05 & 0.04 & & 0.04 & 0.02 & + & 0.04 & 0.02 & $*$ \\
\hline Household income & -0.01 & 0.08 & & 0.09 & 0.04 & $*$ & 0.06 & 0.04 & \\
\hline White $(0=$ other $; 1=$ white $)$ & -0.01 & 0.02 & & 0.00 & 0.01 & & 0.00 & 0.01 & \\
\hline Education & 0.03 & 0.02 & & 0.03 & 0.01 & $* * *$ & 0.03 & 0.01 & $* * *$ \\
\hline $\begin{array}{l}\text { Computer sample } \\
(0=\text { no; } 1=\text { yes })\end{array}$ & -0.10 & 0.05 & + & 0.01 & 0.03 & & 0.02 & 0.02 & \\
\hline $\begin{array}{l}\text { Time period }\left(0=1^{\text {st }} 6 \text { months; }\right. \\
\left.1=2^{\text {nd }} \text { six months }\right)\end{array}$ & 0.04 & 0.03 & & -0.04 & 0.02 & $*$ & -0.09 & 0.01 & $* * *$ \\
\hline Lagged DV & 0.65 & 0.03 & $* * *$ & 0.22 & 0.04 & $* * *$ & 0.11 & 0.04 & $* *$ \\
\hline Extraversion $^{\mathrm{f}}$ & 0.02 & 0.03 & & -0.02 & 0.02 & & 0.00 & 0.01 & \\
\hline Social support $^{\mathrm{g}}$ & 0.03 & 0.04 & & 0.05 & 0.02 & $*$ & 0.01 & 0.02 & \\
\hline Internet use ${ }^{\mathrm{e}}$ & 0.31 & 0.03 & $* * *$ & 0.00 & 0.01 & & -0.03 & 0.01 & $*$ \\
\hline Internet * extraversion & -0.02 & 0.04 & & 0.01 & 0.02 & & 0.03 & 0.02 & \\
\hline Internet $*$ support & 0.10 & 0.05 & $*$ & 0.00 & 0.03 & & 0.00 & 0.02 & \\
\hline Internet $*$ adult & 0.14 & 0.08 & & -0.01 & 0.04 & & 0.01 & 0.04 & \\
\hline$\underline{\mathrm{n}}$ & 400 & & & 403 & & & 403 & & \\
\hline${\underline{\underline{\mathrm{R}^{2}}}}^{2}$ & .71 & & & .15 & & & .15 & & \\
\hline
\end{tabular}

Note. $+\underline{p}<.10, * \underline{p}<.05, * * \mathrm{p}<.01, * * * \mathrm{p}<.001 ;$ Variables were centered before analyses.

${ }^{\mathrm{a}}$ See Table 2; ${ }^{\mathrm{b}}$ Russell, Peplau, \& Cutrona, 1980; ${ }^{\mathrm{c}}$ Radloff, 1977; ${ }^{\mathrm{d}}$ Watson, Clark, \& Tellegen, 1988; ${ }^{\mathrm{e}}$ Watson, et al, 1988; ${ }^{\mathrm{f}}$ see Table 2; ${ }^{\mathrm{g}}$ Heatherton \& Polivy, 1991; ${ }^{\mathrm{h}}$ Bendig, 1962; ${ }^{\mathrm{i}}$ Cohen et al, 1984. 
Figure $1 a$

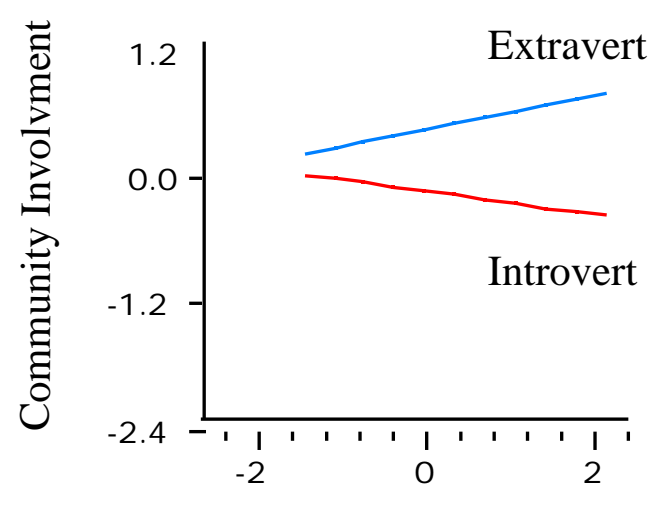

Internet use
Figure $1 b$

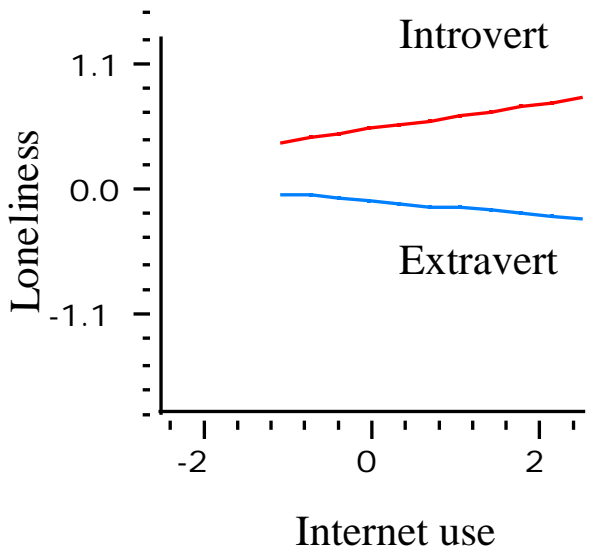

Figure 1. Interaction of Internet Use and Extraversion on Community Involvement and Loneliness.

Note: The plot shows the effects on community involvement and loneliness of Internet use for people differing in extraversion. The plots show predictions from the models reported in Tables 4 and 5 as Internet use and extraversion move through the range appearing in the sample. Internet use varied from 1.12 standard deviations units less than the mean to 2.54 standard deviation units greater than the mean. The Introvert line represents the most introverted respondent, with an extraversion score -2.12 units below the mean, corresponding to a value of 1.10 on the original 5-point Bendig extraversion scale (1962). The Extravert line represents the extraverted respondent, with a score 1.78 units greater than the mean, corresponding to a 5 on the original scale. 
Author bios:

Robert Kraut is Herbert Simon Professor of Human Computer Interaction at Carnegie Mellon University. He has a Ph.D. in Social Psychology from Yale University, has worked as a research scientist at AT\&T Bell Laboratories and Bell Communications Research, and as a faculty member at University of Pennsylvania and Cornell University. He has broad interests in the design and impact of information technology. He has conducted empirical research on office automation and employment quality, technology and home-based employment, the communication needs of collaborating scientists, the design of information technology for smallgroup intellectual work, and the impact of national information networks on organizations and families.

Sara Kiesler is Professor of Human Computer Interaction at Carnegie Mellon University. She has a Ph.D. in Psychology from Ohio State University. Her research examines social aspects of technology and technological change including especially computer communication and human computer interaction. Her projects currently span topics in human-robot interaction, use of information technology in cars, home technology, impact of the Internet, electronic communities and groups, and distributed and multidisciplinary work groups or organizations.

Bonka Boneva is a postdoctoral fellow at the Human Computer Interaction Institute at Carnegie Mellon University. She received a Ph.D. in Sociology from the University of Sofia and has done doctoral work in Psychology at the University of Pittsburgh. She has previously worked at the Bulgarian Academy of Sciences, University of Sofia, Northwestern University and the University of Pittsburgh. Her research and publications include personality factors in 
international and internal migration; re-constructing social identities under new socio-cultural conditions; and power motivation —-theoretical and methodological issues. Recently, she has been studying the impact of gender in computer-mediated communication.

Jonathon N. Cummings is a post-doctoral fellow in the Human-Computer Interaction Institute at Carnegie Mellon University, where he received his $\mathrm{Ph} . \mathrm{D}$. in Organization Science. He earned his BA in Psychology from the University of Michigan and his AM in Social Psychology from Harvard University. He is currently interested in the social impact of Internet use in households and the workplace, interaction processes and performance consequences of distributed work, and statistical analyses and visualization tools for understanding social networks.

Vicki Helgeson is an Associate Professor of Psychology at Carnegie Mellon University. She received her Ph.D. in experimental social psychology from the University of Denver and completed a postdoctoral fellowship in health psychology at UCLA. Her research interests focus on the intersections of gender, relationships, and health. She has conducted a number of longitudinal studies that focus on how people adjust to chronic illness, including breast cancer, heart disease, prostate cancer, and diabetes. Much of this work has been supported by the National Institutes of Health.

Anne M Crawford is a Postdoctoral Fellow at the Human Computer Interaction Institute at Carnegie Mellon University, involved with longitudinal research on the impact of computers, Internet, and other technologies on social relationships and family interaction. Previously, she was Senior Data Analyst for the Pittsburgh Youth Study at the University of Pittsburgh Medical 
Center and Health System for a longitudinal study of substance use and delinquency among adolescent males. She was data analyst for the HIV and Alcohol Prevention Project at the University of Kentucky from 1998-1999. She received her Ph.D. in social psychology from the University of Kentucky in 1998. 